\title{
Parentalidade e o Desenvolvimento Psíquico na Criança ${ }^{1}$
}

\author{
Cássio Marcelo Batista Veludo ${ }^{2}$ \\ Terezinha de Camargo Viana \\ Universidade de Brasilia, Brasília-DF, Brasil
}

\begin{abstract}
Resumo: O artigo analisa o conceito de parentalidade, fundamentado na perspectiva psicanalítica, que permite o estudo tanto da subjetividade dos pais quanto dos filhos. A hipótese é de que a parentalidade, caracteristicamente infiltrada pelo narcisismo dos próprios pais, pode constituir-se como fonte de tensão a partir da qual é possível compreender certas reações que o eu da criança desenvolve e que sinalizam para o maior ou menor sucesso na passagem do princípio de prazer para o princípio de realidade. Ademais, defende-se a importância do estudo dos efeitos causados na subjetividade dos pais por essa infiltração narcisista no amor parental. Este estudo contribui tanto para investigações sobre as psiconeuroses, dado o cotejamento que proporciona entre a clínica e a teoria psicanalítica, como também para a investigação de fenômenos sociais mais complexos como a violência e a desagregação das comunidades humanas.
\end{abstract}

Palavras-chave: Psicanálise, Narcisismo, Relações pais-criança, Winnicott.

\section{Parenthood and Child Psychological Development}

\begin{abstract}
This paper presents an analysis of the concept of parenthood based on the psychoanalytical perspective, which allows the study of both the subjectivity of parents and children. The hypothesis is that parenthood, characteristically infiltrated by the narcissism of parents themselves, can be a source of tension. Based on this premise, it is possible to understand certain responses in the development of a child's ego and which signals success to a greater or lesser extent in the passage from the principle of pleasure to the principle of reality. We also stress the importance of studying effects of this narcissist infiltration of parental love on the subjectivity of parents. This study contributes both to investigations addressing psychoneurosis, based on a comparison provided between clinical practice and psychoanalytical theory, and to the investigation of more complex social phenomena such as violence and the disaggregation of human communities.
\end{abstract}

Keywords: Psychoanalysis, Narcissism, Parent Child Relations, Winnicott.

\section{Parentalidad y Desarrollo Psicológico de Niños}

Resumen: Este artículo analiza un concepto de parentalidad, basado en la perspectiva psicoanalítica, que permite el estudio de la subjetividad de los padres y de los hijos. La hipótesis es que la parentalidad, característicamente enraizada por el narcisismo de los propios padres, puede constituirse como punto de partida para la comprensión de algunas reacciones que el yo de los niños desarrolla y que apuntan al mayor o menor éxito en la transición del principio de placer al principio de la realidad. Además, destacamos la importancia del estudio sobre los efectos que la subjetividad de los padres causan por esa marca narcisista en el amor parental. Este estudio puede contribuir al estudio de las psiconeurosis, por la comparación que ofrece entre la clínica y la teoría psicoanalítica, y también a la investigación de los fenómenos sociales más complejos como la violencia y la desintegración de las comunidades humanas.

Palabras clave: Psicoanálisis, Narcisismo, Relaciones Padres-niños, Winnicott.

Este artigo é fruto de um percurso de estudo sobre as marcas narcísicas na parentalidade e das relações que podem ser estabelecidas entre estas e o desenvolvimento psíquico na criança (Veludo, 2009). A hipótese sobre a qual nos debruçaremos é a de que a parentalidade, marcada pelo narcisismo, interfere na passagem do princípio de prazer para o princípio de realidade, influenciando, dessa forma, o desenvolvimento infantil. Para apoiar nossa elaboração, destacamos a

\footnotetext{
${ }^{1}$ Artigo derivado da Dissertação de Mestrado do primeiro autor sob orientação da segunda autora, defendida em 2009 no Programa de Pósgraduação em Psicologia Clínica e Cultura do Instituto de Psicologia da Universidade de Brasília.

${ }^{2}$ Endereço para correspondência:

Cássio Marcelo Batista Veludo. Setor de Mansões Park Way, Quadra 28, Conjunto 4 Lote 1 Casa D. CEP 71.745-804. Brasília-DF, Brasil. E-mail: cassioveludo@hotmail.com
}

importância, para este estudo, do conceito de ambiente suficientemente bom (Winnicott, 1975, 1977) e das teorias freudianas sobre a pulsão e o estado de desamparo, característico dos primeiros anos de vida.

Com o intuito de iniciar a discussão, apresentamos um conceito de função parental elaborado por Algarvio, Leal, Maroco e Serra (2008). As autoras definem a função parental como um equilíbrio satisfatório entre o investimento narcísico e o objetal nos filhos. Tal definição tem o mérito de estabelecer uma relação entre o tema da parentalidade e o do narcisismo, ainda que não nos permita afirmar o que, em última análise, poderia ser essa função. Em outras palavras, sinaliza para o fundamento libidinal da parentalidade sem, contudo, delimitar com clareza o que significam termos como "equilíbrio" e "satisfatório". Esse impasse, todavia, não criará maiores dificuldades para a reflexão sobre o conceito de parentalidade, principalmente se pudermos seguir a 
própria indicação das autoras sobre as bases teóricas que as orientaram na construção de sua tese. E, se assim o fizermos, encontraremos a indicação do quão determinante para esse conceito são algumas noções propostas por Winnicott, em especial as que remetem ao papel da família no desenvolvimento infantil.

\section{Parentalidade Suficientemente Boa}

Winnicott (1975), ao desenvolver o tema dos fenômenos transicionais, propõe uma tese sobre a função dos pais ao afirmar que:

Nas primeiras fases do desenvolvimento emocional do bebê humano, um papel vital é desempenhado pelo meio ambiente, que, de fato, o bebê ainda não separou de si mesmo. Gradativamente a separação entre o não-eu e o eu se efetua, e seu ritmo varia de acordo com o bebê e com o meio ambiente. As modificações principais realizam-se quanto à separação da mãe como aspecto ambiental objetivamente percebido. Se ninguém ali está para ser mãe, a tarefa desenvolvimental do bebê torna-se infinitamente complicada (p. 153).

Alguns pontos chamam atenção nesse trecho. Primeiramente, vemos apresentada uma concepção em que o bebê humano é claramente definido por sua completa ligação com o meio ambiente que o recebe, o que caracteriza um estado de total fusão com este meio. É a partir desta fusão do início da vida que, segundo Winnicott (1975), acontece algo de singular importância para o desenvolvimento humano, isto é, o bebê passa a olhar em volta e se depara com o rosto da mãe, momento no qual, "normalmente, o que o bebê vê é ele mesmo" (p. 154). Este papel de espelho, contudo, nem sempre pode ser desempenhado pela mãe, ou seja, nem sempre os bebês recebem de volta aquilo que estão dando; quando isso ocorre, o que se reflete é o próprio humor da mãe, “ou, pior ainda, a rigidez de suas próprias defesas" (p. 154). Bebês expostos por muito tempo a essa situação acabariam atrofiados em sua capacidade criativa e buscariam outras maneiras de "obter algo de si mesmos de volta, a partir do ambiente" (p. 155 ), tais como agressividade, adoecimento ou qualquer outra situação que possa acabar gerando dificuldades ou aborrecimentos para os pais.

Esse aspecto da função ambiental desempenhada pelos pais tem extremo valor para as considerações concernentes à clínica. Se observarmos atentamente, seremos capazes de perceber uma ligação estreita, proposta por Winnicott (1975), entre o desempenho das funções parentais e determinados problemas que acabam futuramente conduzindo a criança ao consultório. Mencionamos funções parentais, e não função maternal, pois ainda que a figura da mãe receba especial atenção na teoria winnicottiana, o próprio autor sempre se apressa a indicar a importância do pai no processo de desenvolvimento dos filhos. A esse respeito, talvez baste lembrar a própria opinião de Winnicott que em diversos momentos inclui os pais em sua tese, ainda que lhes peça permissão para continuar utilizando o termo maternal na definição da atitude suficientemente boa no cuidado com os bebês:

O termo "paternal" tem de vir necessariamente depois do termo 'maternal'. Gradativamente o pai, como indivíduo do sexo masculino, torna-se um fator significativo. Depois, segue-se a família, cuja base é a união de pais e mães, numa partilha de responsabilidade por aquilo que fizeram juntos, aquilo que chamamos de um novo ser humano, um bebê (p. 191).

Nessa perspectiva, as funções de pais e mães, no que se refere ao cuidado suficientemente bom de seus bebês, devem ser tão intimamente imbricadas que se torna difícil a tarefa de definir claramente os limites de uma e de outra e ainda mais complicado afirmar quem seria mais importante, se as mães ou os pais. É claro que geralmente observamos em nossa sociedade uma apropriação maior nos cuidados com o bebê por parte da mãe ou, em outras palavras, uma presença maior da mãe. Isso se explica, em parte, pela prática da amamentação e outros cuidados básicos que, costumeiramente, ficam sob responsabilidade materna. Contudo, não nos parece algo tão evidente pressupor que durante esse período de interação mais intensa entre mãe e bebê, a figura paterna não exerça sua influência sobre a criança ou o faça de maneira muito incipiente, ou ainda, somente de forma indireta.

Vale ressaltar, ainda, que não estamos propondo uma equivalência entre a função paternal e a maternal, afirmando que ambas seriam a mesma coisa, ou ainda, que seria indiferente para o bebê se pais e mães trocassem de funções entre si. Ademais, tentaremos evitar uma discussão de gênero, não por a considerarmos desprovida de utilidade, mas simplesmente porque nos afastaria em demasia de nossos objetivos.

Se concordarmos com a posição defendida por Winnicott (1975), teremos que aceitar que o desenvolvimento da criança sofre, em última análise, influência decisiva daquilo que, primeiramente a mãe e, gradativamente, o pai, têm a lhe oferecer e isso se daria de forma tão peremptória que o autor chega a afirmar categoricamente que "não há possibilidade alguma de um bebê progredir do princípio do prazer para o princípio da realidade ou no sentido, e para além dela, da identificação primária, a menos que exista uma mãe suficientemente boa" (p. 25).

Contudo, em outra obra também de sua autoria, Winnicott (1977) é menos taxativo ao anunciar o papel que essa influência (parental) exerce na constituição da criança, pois afirma que "cada bebê é uma organização em marcha" (p. 29), possuidor de uma centelha inata de vida que impele para frente seu crescimento e desenvolvimento, independentemente dos pais. Conclui, mais à frente, dizendo que, se a 
mãe aceitar essa perspectiva sobre seu bebê, então conseguirá se libertar o bastante para observar o desenvolvimento da criança, "enquanto desfruta o prazer de reagir às suas necessidades" (p. 30).

Primeiramente, Winnicott (1975) é claro ao considerar a maternagem como elemento fundamental na constituição da subjetividade da criança. A seguir, o próprio Winnicott (1977) afirma algo aparentemente diverso, isto é, que o bebê não careceria tanto de sua mãe, pois já nasceria com o empuxo necessário para seguir adiante, tendo a maternagem uma mera função reativa. Além do fato de que a obra de 1977 foi declaradamente destinada ao público leigo, argumento que poderia ser utilizado para justificar uma menor preocupação conceitual, enquanto que a publicada em 1975 teria um acabamento mais técnico, como poderíamos interpretar esse direcionamento dúbio que Winnicott parece dar para a função dos pais na constituição dos filhos?

Talvez encontremos uma saída para essa ambiguidade se entendermos ambas as propostas como complementares e não como excludentes. Ao afirmar que o bebê não depende da mãe para crescer e se desenvolver, Winnicott (1977) pretende circunscrever aquilo que ele reconhece de inato no ser humano, ou seja, uma "tendência para a vida e o desenvolvimento" (p. 29). Esta tendência, por si só, seria capaz de produzir a vivacidade necessária para impulsionar o crescimento, independentemente das ações parentais. Uma tendência, contudo, não significa a garantia de realização e talvez seja nesse sentido que Winnicott (1975) afirme a imprescindibilidade da mãe suficientemente boa para a superação do princípio do prazer.

Se de um lado temos a criança, com aquilo que seria inato em sua aparelhagem biológica e psíquica, do outro, deparamo-nos com a exposição prematura desta aparelhagem aos estímulos do mundo externo e interno. Tal configuração, aliás, é a base do estado de desamparo em que o organismo se encontra no início da vida, quando "não pode provocar a ação específica capaz de suprimir a tensão resultante do afluxo das excitações endógenas [necessitando] do auxílio de uma pessoa exterior (fornecimento de alimentação, por exemplo)" (Laplanche \& Pontalis, 2001, p. 531). Ou seja, o organismo prematuro e inábil para suprir suas próprias necessidades depende de um meio que realize essa função.

Poderíamos considerar que essa centelha vital inata indicada por Winnicott (1977) corresponde à estimulação pulsional característica da espécie humana? Além disso, seria correto afirmar que o psiquismo infantil torna-se suscetível à influência subjetiva de um adulto - os pais em especial - devido ao efeito da imaturidade biológica e psicológica inerentes ao estado de desamparo? Entendemos ser possível responder ambas as questões de maneira afirmativa e, caso não estejamos equivocados em nosso julgamento, deparamonos com uma excelente oportunidade para estabelecer um diálogo entre alguns conceitos freudianos - especialmente as teorias sobre a pulsão e sobre o estado de desamparo - e a tese winnicottiana do ambiente suficientemente bom como um protótipo de parentalidade capaz de auxiliar a criança na passagem do princípio de prazer para o de realidade.

\section{Parentalidade sob uma Perspectiva Freudiana}

Laplanche e Pontalis (2001) destacam a importância do estado de desamparo para a teoria freudiana da angústia, afirmando que este estado seria o "protótipo da situação traumática" (p. 112). Realmente parece ser essa a perspectiva explicitada por Freud (1915/2004b), quando postula que "o sistema nervoso é um aparelho ao qual foi conferida a função de livrar-se dos estímulos que lhe chegam, de reduzi-los a um nível tão baixo quanto possível, ou, se fosse possível, de manter-se absolutamente livre de estímulos" (p. 147). Temos aqui enunciados tanto o princípio do zero ou do nirvana, que posteriormente sustentará toda a elaboração acerca da pulsão de morte, quanto o princípio da constância, que se baseia na definição de prazer e desprazer como a diminuição ou o aumento, respectivamente, da estimulação sobre o sistema nervoso. Sob esse ponto de vista metabiológico, o trauma seria, portanto, um acontecimento ocasionado pelo aumento de uma estimulação que, devido "ao longo tempo durante o qual o jovem da espécie humana está em condições de desamparo e dependência" (Freud, 1926/1996d, p. 151), não encontra os meios necessários para uma descarga motora que gere uma vivência de satisfação.

O estado de desamparo parece, portanto, ser também um conceito-chave para nossa reflexão sobre a parentalidade, pois delineia um fundamento importante sobre o qual tentaremos sustentar a ligação entre funcionamento psíquico da criança e subjetividade parental. Assim, percebemos que o encurtamento da vida uterina faz com que o bebê da espécie humana chegue ao mundo num estado bem menos acabado, quando comparado a outros animais; o resultado disso é que

a influência do mundo externo real sobre ele é intensificada e uma diferenciação inicial entre o ego e o id é promovida. Além disso, os perigos do mundo externo têm maior importância para ele, de modo que o valor do objeto que pode somente protegê-lo contra eles e tomar o lugar da sua antiga vida intrauterina é enormemente aumentado. O fator biológico, então, estabelece as primeiras situações de perigo e cria a necessidade de ser amado que acompanhará a criança durante o resto de sua vida (Freud, 1926/1996d, p. 151).

Ou seja, cremos ser possível encontrar nessa passagem uma janela por meio da qual se vislumbra uma relação entre as subjetividades da criança e dos pais. A necessidade de ser amada, que surge como substrato de fatores biológicos, forçaria a criança a aceitar as restrições impostas a suas pulsões sexuais pelo objeto capaz de suprir suas necessidades. Manter o amor deste objeto, portanto, tornar-se-ia tarefa fundamental para a criança. As bases desta relação seriam 
estabelecidas desde muito cedo, a partir do momento em que a criança percebe, por experiência própria, que sua mãe, quando presente, "satisfaz todas as suas necessidades sem delongas” (Freud, 1926/1996d, p. 136). Winnicott talvez acrescentasse que isso ocorreria somente se esta mãe fosse suficientemente boa para seu bebê, o que, a rigor, não parece ser algo diferente do que é proposto na passagem freudiana.

É importante ressaltar, contudo, que Freud não emite parecer definitivo sobre esse ponto relacional que ora tentamos explorar. Para sermos precisos, há momentos em sua obra nos quais ele claramente se posiciona incisivamente como partidário da ideia de que o desenvolvimento do psiquismo seria impulsionado por forças cujas fontes residiriam no interior do organismo, tendo os estímulos externos pouca influência sobre esse processo. Por outro lado, é possível encontrar passagens em que o aspecto relacional parece surgir com bastante força, no sentido de ser capaz até de determinar a conformação pulsional.

Essa dualidade se expressa, por exemplo, em Pulsões e destinos de pulsões ainda que nesse momento seja difícil não notar o posicionamento mais decidido de Freud (1915/2004b) no que tange à diminuição da importância dos estímulos externos. Em certo ponto do texto, durante uma discussão sobre o desenvolvimento que a pulsão exige do sistema nervoso, ele afirma ser possível concluir que os verdadeiros motores dos progressos que levaram o sistema nervoso ao seu atual nível de desenvolvimento são as pulsões e não os estímulos externos, ainda que nada nos impeça de encarar as pulsões como "precipitados da ação de estímulos externos que, no curso da filogênese, modificaram a substância viva" (p. 148).

Nesse mesmo texto, porém, quando descreve como seria o início da vida, Freud parece abandonar a ambiguidade, sendo mais taxativo quanto a essa questão ao nos apresentar um eu que se encontra tomado de pulsões e é capaz de satisfazê-las, pelo menos em parte, em si mesmo. Nesse estado narcísico de satisfação autoerótica, o eu não investiria de interesse o mundo externo que, então, tornar-se-ia irrelevante no tocante à satisfação pulsional. Assim, Freud conclui que o eu-sujeito passa a coincidir com tudo o que sinaliza o prazer, e "o mundo externo, com tudo o que é indiferente (e eventualmente, como fonte de estímulos, com o que é desprazeroso)" (Freud, 1915/2004b p. 158).

Em outras palavras, o eu, nesse momento, não necessitaria do mundo externo, na medida em que obteria toda a satisfação de que necessita de forma autoerótica. Assim, a questão relacional torna-se bastante insignificante e isso configura uma das interpretações que, segundo Laplanche (1998), percorrem todo o pensamento psicanalítico, isto é, a ideia que faria do narcisismo uma "espécie de circuito fechado, de mônada autossuficiente, onde já não se distinguiriam um sujeito e um objeto (uma espécie de estado primordial autossuficiente, fechado sobre si mesmo)" (p. 304). Há, contudo, outra interpretação presente no pensamento psicanalítico definindo o narcisismo como "amor dirigido ao ego (portanto, já numa espécie de distinção tópica interna), sendo este constituído numa relação direta com o outro" (Laplanche, p. 304). O autor sugere, portanto, a necessidade de imaginar uma espécie de relação original que seria, ao mesmo tempo, amor e identificação.

Esta segunda perspectiva, que, aliás, o próprio Laplanche (1998) afirma encontrar em Freud, especialmente no artigo Luto e Melancolia, é essencial para nossa discussão, considerando que buscamos fundamentos que nos permitam falar de uma parentalidade como estrutura que influencia a subjetividade dos filhos. Vislumbramos certa limitação na perspectiva da mônada fechada e autossuficiente, ao menos naquilo que tal forma de entendimento tem de radical e exclusivista. Não se trata, portanto, de uma simples escolha baseada na preferência ou na conveniência, pois é fundamental que se possa buscar o sentido e a importância de cada uma dessas interpretações. Se por um lado, tratar o psiquismo como essa mônada autossuficiente pode limitar o aspecto relacional destacado por Laplanche, por outro pode nos ajudar a compreender a importância das forças pulsionais que estão na base dos fenômenos aqui estudados, possibilitando-nos, talvez, ir além de uma análise puramente fenomenológica que nos afastaria da compreensão das estruturas e processos psíquicos que estão em curso. Da mesma forma, uma excessiva ênfase estrutural que não busque no contexto histórico e cultural as influências que concorrem para a constituição do sujeito também pode deixar de fora elementos importantes para a análise.

Como dito anteriormente, Laplanche cita o artigo Luto e Melancolia como fonte importante dessa perspectiva freudiana menos voltada para a concepção do psiquismo humano como uma mônada independente. Entretanto, no artigo sobre o narcisismo publicado alguns anos antes, Freud (1914/2004a) já expressava determinadas ideias que poderiam fortalecer essa interpretação sobre uma relação original capaz de influenciar a subjetividade da criança. Ao discutir a gênese do ideal de eu, o autor afirma que:

Na verdade, foi a influência crítica dos pais que levou o doente a formar seu ideal de eu, que lhe é transmitido pela voz e tutelado pela consciência moral; mais tarde, somam-se a esse ideal as influências dos educadores, dos professores, bem como de uma miríade incontável e indefinível de todas as outras pessoas do meio (os outros, a opinião pública) (p. 114).

A voz é o instrumento destacado por Freud e, anterior a qualquer outra influência, é a voz dos pais que aparece como função crítica e formadora do ideal de eu para o qual a libido narcísica poderá então fluir. Ora, podemos identificar como base para essa função crítica na formação da subjetividade da criança justamente a condição de desamparo na qual ela se encontra e que a coloca refém do amor parental. Pouco resta senão tentar, de todas as maneiras possíveis, garantir esse amor e, portanto, lutar contra tudo aquilo que possa 
colocar em risco esse sentimento tão importante para sua sobrevivência. Poucas coisas podem oferecer mais risco para a criança nesse momento do que os estímulos incessantes de sua própria vida pulsional, especialmente quando entram em choque com aquilo que seus pais lhe apontam como impróprio ou indevido. Assim, poderíamos entender como o amor impõe um freio ao narcisismo infantil, atuando como fator de civilização (Freud, 1921/1996c), e como a consciência de merecer esse amor, posteriormente sentida pelo adulto com imenso orgulho, remete-nos a experiências infantis muito antigas de segurança e satisfação ligadas à renúncia pulsional por amor aos pais (Freud, 1939/1996e).

A partir do precioso estudo de Freud sobre o narcisismo, é possível perceber como o desenvolvimento do eu está intimamente ligado à conformação narcísica da libido durante a infância, o que talvez nos permita falar em uma tendência inata no ser humano para uma conduta egoísta e hostil, especialmente quando seus desejos e necessidades não são atendidos. Catorze anos antes da publicação de seu escrito princeps sobre o narcisismo, Freud (1900/1987) já estava atento para essa tendência ao egoísmo, chegando mesmo a afirmar que as crianças são "completamente egoístas (...) sentem suas necessidades intensamente e lutam de maneira impiedosa para satisfazê-las, especialmente contra os rivais, outras crianças, e acima de qualquer outra coisa, contra seus irmãos e irmãs" (p. 264).

Esta tendência, contudo, pode tanto ser intensificada como reprimida e parece ser possível afirmar que ambas formas guardam íntima relação com processos psicológicos fundamentados na subjetividade parental que se expressam no maior ou menor desejo, por parte das figuras parentais, de coibir ou alimentar, nos filhos, determinados valores e padrões de conduta. Não é incomum encontrarmos na clínica casos em que determinados comportamentos da criança são motivos para as queixas parentais ao mesmo tempo em que são aceitos e até mesmo incentivados por eles, ainda que de forma inconsciente. A análise desses casos conduz-nos à questão da revivescência narcísica que caracteriza o amor dedicado aos filhos (Freud, 1914/2004a), um amor que, nesse sentido, volta-se muito mais para si mesmo do que para os filhos propriamente ditos.

\section{O Narcisismo Marca a Parentalidade}

Resgatemos nesse momento os conceitos sobre o estado de desamparo, os dois princípios do funcionamento psíquico e o ambiente suficientemente bom, com o objetivo de confrontá-los com essa ideia da influência crítica dos pais na constituição da subjetividade infantil para podermos, num exercício de síntese, classificar a parentalidade como fator determinante no desenvolvimento da criança no que se refere à complexa e quase sempre perturbadora passagem do princípio de prazer para o princípio de realidade.

Esta derivação no conceito de parentalidade, todavia, não deve nos remeter a um estado observável de coisas ou a um fenômeno que poderia ser descrito a partir da caracterização de estilos de parentalidade. Parece-nos mais correto tratar esse conceito não como um fato da observação, mas como uma estrutura, uma construção teórica a partir da qual podemos estudar as relações existentes entre um "acontecimento inelutável do desenvolvimento" (Green, 1988, p. 241), isto é, a perda do objeto e o excesso pulsional que marca o investimento parental nos filhos, um excesso que remete à ferida narcísica dos pais:

Não pode haver muito: muito amor, muito prazer, muito gozo, enquanto, do outro lado, a função parental está sobreinvestida. No entanto, esta função está, na maioria das vezes, infiltrada pelo narcisismo. As crianças são amadas com a condição de preencherem os objetivos narcisistas que os pais não conseguiram realizar (p. 256).

Essa infiltração narcísica que, segundo Green, está na maioria das vezes presente na parentalidade, surgiria, pois, como um fator de perturbação contra o qual os mecanismos de defesa do eu da criança precisarão se erguer. Nesse caso, poderíamos nos adiantar e indagar se seria plausível pensar numa relação entre pais e filhos na qual os objetivos narcísicos dos primeiros não estivessem, como pano de fundo, impulsionando o sobreinvestimento parental? Provavelmente não. Ademais, se concordarmos com o conceito de função parental proposto por Algarvio et al. (2008), não estaremos autorizados a conceber as relações entre pais e filhos como exclusivamente constituídas por investimentos narcísicos ou por objetais, e sim, como uma função derivada da tensão de ambos os tipos de investimento.

Ou seja, se por um lado a marca narcísica no amor parental pode fundamentar uma série de perturbações na relação entre pais e filhos, por outro, não nos pareceria correta a tentativa de caracterizar a parentalidade suficientemente boa como o campo dos investimentos objetais livres de marcas narcísicas e que, agindo dessa forma, ou seja, amando os filhos por eles mesmos e não pelos objetivos narcísicos que preenchem, os pais estariam contribuindo para que a criança superasse o desamparo e a perda do objeto, submetendo-se, assim, aos desígnios do princípio de realidade. Menos correto ainda seria buscar nessa suposta parentalidade livre de marcas narcísicas a solução final para poupar a criança do sofrimento advindo de sua incompletude e desamparo. Aliás, poucas buscas seriam mais marcadas pelo narcisismo do que esta.

Dito de outra forma, a parentalidade, da maneira como a estamos considerando, não deve ser tratada como uma capacidade a ser desenvolvida nos pais que, então, estariam aptos a evitar, na criança, o sofrimento advindo da perda do objeto, ou então, como uma maneira de evitar tal sofrimento. Sabemos, a partir da teoria psicanalítica, que esta perda é um "momento fundamental da estruturação do psiquismo humano durante o qual se instaura uma nova relação com a realidade" (Green, 1988, p. 241). Assim, se pretendemos 
defender para a parentalidade uma função estruturante, torna-se inaceitável a expectativa de utilizar tal conceito para pré-definir ou julgar os tipos específicos de conduta que os pais deveriam desenvolver para ajudar seus filhos na vivência desse período estruturante para o psiquismo.

Por outro lado, o estudo da subjetividade parental pode contribuir para que, em cada caso, o clínico consiga ajudar os pais a conhecer e, talvez, elaborar os objetivos narcísicos que depositam em seus filhos e identificar em que medida esse depósito pode contribuir com a conformação dos conflitos vividos. Se a perda do objeto é inevitável, isso não significa dizer que devamos abandonar todo e qualquer esforço para entender os fatores que podem perturbar esse momento já bastante conturbado do desenvolvimento. Nesse sentido, a parentalidade poderia ser compreendida como a manifestação de uma estrutura psíquica parental que se conecta, desde o início, ao desenvolvimento da criança, estrutura esta caracterizada, por um lado, pelos objetivos narcisistas que os pais buscam preencher por meio dos filhos e, por outro, pelo investimento objetal que também lhes destinam, sendo muito difícil definir com clareza as fronteiras de cada um desses dois tipos de investimento.

A ideia de um ambiente suficientemente bom, como definido por Winnicott (1975), parece entrar em ressonância com essa concepção, e não com uma que tentasse identificar a postura parental capaz de adivinhar e realizar todos os desejos e necessidades da criança, postura esta, aliás, que seria muito mais condizente com a lógica do princípio de prazer do que com a instalação do princípio de realidade. Os pais ocupariam, nessa transição entre os princípios de funcionamento do aparelho psíquico, um lugar de destaque devido ao investimento especial que desde o início estão aptos a receber de seus filhos. Estes, desamparados que se encontram em suas constituições psíquicas ainda rudimentares, precisam que o investimento parental recaia sobre eles e, assim, os ajude a lidar com os mortíferos estímulos de origem endógena e exógena. Contudo, essa ajuda parental jamais será suficiente, especialmente no que se refere à vida pulsional da criança, criando mais um problema para o psiquismo infantil já sobrecarregado. Ainda que os pais obtenham certo sucesso na proteção da criança contra perigos externos, pouco pode ser feito em relação às demandas pulsionais que tomam de assalto o psiquismo infantil, especialmente as de caráter sexual.

Essa situação torna-se ainda mais complexa quando levamos em consideração as consequências que a marca narcísica na parentalidade pode imprimir na relação entre pais e filhos. Tal marca apontaria tanto para a existência de objetivos parentais de natureza narcisista como para a impossibilidade de realização destes objetivos. Em outras palavras, a marca narcísica na parentalidade delimita o próprio sofrimento pela vivência primitiva da perda do objeto primário dos pais. Se recordarmos o conceito de mãe suficientemente boa proposto por Winnicott (1975), poderíamos utilizá-lo para entender a insuficiência da postura parental infiltrada pelo narcisismo como resultado da reação frente a determinadas características da criança que abalam gravemente os objetivos parentais narcisistas e, com isso, reavivam essa experiência primária de perda do objeto de amor dos pais. O que poderia ocorrer nesses casos é que a criança também não consegue ser para os pais um objeto suficientemente bom ou, pelo menos, não um que possa ser "colocado no lugar do ideal de ego" (Freud, 1921/1996c, p. 123) parental.

Enfatizamos, aqui, a importância da sexualidade como fator traumático. Se discorremos anteriormente sobre a tensão vivida pela criança na tentativa de conciliar sua vida pulsional com as exigências do mundo externo, especialmente a voz parental, agora podemos vislumbrar, por outro ângulo, os conflitos que a vivência da parentalidade podem gerar na economia pulsional dos pais. Convém esclarecer, de pronto, que essa ênfase no caráter perturbador da pulsão sexual não é nossa invenção. É em Freud (1940/1996f) que encontramos essa referência quando, por exemplo, nos explica no Esboço de Psicanálise, como o atraso do desenvolvimento do ego promove um fracasso na tarefa de dominar determinadas excitações sexuais numa época primitiva da vida:

É nesse atraso do desenvolvimento do ego em relação ao desenvolvimento libidinal que vemos a pré-condição essencial da neurose, e não podemos fugir à conclusão de que as neuroses poderiam ser evitadas se se poupasse ao ego infantil essa tarefa isto é, se à vida sexual da criança fosse concedida liberdade de ação, como acontece entre muitos povos primitivos (p. 214).

Ou seja, de todas as exigências que o psiquismo da criança precisa enfrentar sem ainda possuir as melhores condições para esse combate, destacam-se as próprias pulsões sexuais do sujeito bem como as repressões sofridas contra estas pulsões. Assim, parece-nos cada vez mais difícil desconsiderar a importância de compreender os fatores de perturbação da subjetividade parental como mecanismos capazes de exercer influência decisiva no desenvolvimento psicossexual da criança, especialmente se levarmos em consideração que as reações defensivas que se constituem como forma de lidar com a tensão gerada pela vivência da perda do objeto de amor marcam tanto o psiquismo infantil como o parental, ainda que, neste caso, estejamos falando de uma revivescência da perda objetal primitiva atualizada e transferida para a relação com os filhos.

Poderíamos questionar como um sujeito, reprimido em sua sexualidade, marcado narcisicamente por sua própria vida pulsional e, dessa forma, vivendo a infindável tensão entre os dois princípios do funcionamento psíquico, enfim, como um sujeito assim caracterizado lida com a experiência de ter, sob seus cuidados, outro psiquismo vivendo conflitos semelhantes? Uma primeira resposta seria: repassando a repressão para os filhos. Uma observação atenta nos mostra como os pais são os primeiros encarregados de reprimir a sexualidade que já se encontra pujante no bebê e, talvez, 
com isso lancem os primeiros diques contra a livre fluência do princípio de prazer. Como vimos anteriormente, recebem nessa tarefa um auxílio inestimável da situação de desamparo na qual seus filhos lhes são entregues pela vida. $\mathrm{O}$ eu fraco e imaturo, especialmente no primeiro período de infância, encontra-se permanentemente atacado por tensões contra as quais seus esforços são pouco efetivos. As crianças são capazes de sobreviver porque "são protegidas contra os perigos que as ameaçam do mundo externo pela solicitude dos pais; pagam esta segurança com um temor de perda de amor que as deixaria desamparadas face aos perigos do mundo externo" (Freud, 1940/1996f, p. 213).

Dessa forma, as figuras parentais podem servir de referência para que a criança tente a realização de um grande projeto, isto é, a renúncia ao princípio de prazer. Ou melhor, diríamos que nem tanto a figura parental, mas o amor, ou ainda, o temor da perda do amor desta figura, sem o qual a criança pereceria em sua luta pela vida. Vislumbramos, assim, um mecanismo de repressão da sexualidade que, desde o início, acaba sendo exercido pelos pais sobre a criança.

Contudo, talvez possamos também encarar a parentalidade como fonte de estímulo para a consolidação do princípio de prazer e não para sua renúncia. Nesse caso, a parentalidade apresentar-se-ia como fonte de perturbação da sexualidade infantil não por reprimi-la, mas por oferecer-lhe estímulos que podem contribuir para sua fixação em etapas primitivas do desenvolvimento psicossexual. Talvez seja possível afirmar que determinadas demandas de ordem narcísica, criadas a partir da subjetividade parental, encontrem ressonância no psiquismo infantil e, por meio do confronto psíquico entre pais e filhos, interfiram na forma como os filhos são tratados e, por conseguinte, na forma como se desdobra o desenvolvimento psíquico da criança.

\section{Considerações Finais}

Nosso objetivo neste trabalho é argumentar em favor de um conceito de parentalidade que, fundamentado na perspectiva psicanalítica, nos permita estudar tanto a subjetividade parental quanto a subjetividade da criança. Entendemos que um conceito de parentalidade assim concebido viabiliza o estudo da infiltração do narcisismo parental no amor dedicado aos filhos, bem como o efeito que essa infiltração pode provocar na subjetividade da criança. A hipótese que lançamos é de que essa configuração da relação entre pais e filhos, notadamente marcada por infiltrações de ordem narcisista, pode nos ajudar na compreensão de certas reações que o eu da criança desenvolve, reações que demarcam o maior ou o menor sucesso na passagem do princípio de prazer para o princípio de realidade.

Apoiamo-nos em Winnicott (1975) para definir a parentalidade suficientemente boa como aquela capaz de auxiliar a criança nessa consolidação do princípio de realidade. É válido ressaltar que não defendemos uma dicotomia entre os dois princípios do funcionamento psíquico, inclusive por concordamos com a ideia de que a substituição do princípio de prazer "pelo princípio de realidade não implica a deposição daquele, mas apenas sua proteção. Um prazer momentâneo, incerto quanto a seus resultados, é abandonado, mas apenas a fim de ganhar mais tarde, ao longo do novo caminho, um prazer seguro" (Freud, 1911/1996a, p. 242). Agindo dessa forma, o psiquismo tenta se proteger das pressões causadas pela influência da instrutora necessidade e se vê compelido a renunciar à satisfação imediata:

O ego descobre que lhe é inevitável renunciar à satisfação imediata, adiar a obtenção de prazer, suportar um pequeno desprazer e abandonar inteiramente determinadas fontes de prazer. Um ego educado dessa maneira tornou-se "racional"; não se deixa mais governar pelo princípio de prazer, mas obedece ao princípio de realidade que, no fundo, também busca obter prazer, mas prazer que se assegura levando em conta a realidade, ainda que seja um prazer adiado ou diminuído (Freud, 1917/1996b, p. 360).

Assim, se defendemos um conceito de parentalidade suficientemente boa é com o objetivo de produzir uma ferramenta que nos permita olhar para a relação entre pais e filhos e pesquisar determinados processos de subjetivação na criança e nos pais a partir do referencial psicanalítico, levando em consideração esse passo que Freud aponta como um dos mais importantes na direção do desenvolvimento do eu, ou seja, a passagem do princípio de prazer para o de realidade. Nesse sentido, tentamos demonstrar como a força de determinados objetivos narcisistas na subjetividade parental pode ofuscar para os pais a capacidade de oferecer um ambiente suficientemente bom para o desenvolvimento da criança. Ao utilizar o termo criança suficientemente boa tentamos enfatizar o potencial conflito existente entre as idealizações narcisistas que os pais tentam preencher por meio do amor dedicado aos filhos e as necessidades externas apresentadas diariamente pela criança.

Parece-nos possível supor que a marca narcísica na parentalidade sinaliza para uma tendência mais ou menos irresistível para a eleição da criança interna, fruto da idealização dos pais e, consequentemente, para o abandono da criança externa que se encontra sob seus cuidados. Os pais se esforçam além dos limites para que a criança idealizada possa ter melhor sorte e não precise obedecer aos mesmos imperativos aos quais eles se submeteram ao longo da vida:

Doença, morte, renúncia à fruição, restrições à própria vontade não devem valer para a criança; as leis da natureza, assim como as da sociedade, devem se deter diante dela, e ela deve realmente tornar-se de novo o centro e a essência da criação do mundo. His Majesty the baby, tal como nós mesmos no imaginamos um dia (Freud, 1914/2004a, p. 110). 
Nesse ínterim, podemos imaginar um cenário de verdadeiro abandono do filho externo, especialmente se suas demandas divergirem desse projeto de perfeição tão caro para os pais. Na prática, poderíamos descrever aqui como esse desejo de revogar as leis da natureza e da sociedade pode fundamentar uma postura permissiva extremada em relação aos comportamentos e desejos da criança. Em outras palavras, ao tentar preservar seus objetivos narcisistas, os pais acabariam estimulando a supremacia do princípio de prazer no aparelho psíquico da criança.

As possíveis consequências desse arranjo familiar podem nos conduzir tanto para o estudo de caráter mais clínico das psiconeuroses como para investigações mais amplas ligadas aos fenômenos sociais. Afinal, se por um lado a compreensão do funcionamento psíquico descortina diante de nós componentes importantes dos conflitos psíquicos, por outro, não deixamos de perceber a possibilidade de utilizar esta mesma compreensão para estudar fenômenos mais amplos como, por exemplo, a agregação ou desagregação social, a conduta delinquente, a violência urbana, entre outros aspectos da vida humana que, em nosso entendimento, podem ser compreendidos como expressões da forma como os sujeitos e as comunidades se posicionam frente à obtenção do prazer, a saber, formas imediatas, sem se importar com as consequências para si e para outros membros da comunidade, ou formas mediatas, com significativa redução no prêmio da satisfação, contudo, com um ganho civilizatório duradouro.

\section{Referências}

Algarvio, S., Leal, I., Maroco, J., \& Serra, A. M. (2008). Preocupações parentais: Estudo comparativo entre grupo de pais normativo e um grupo de pais de crianças nascidas por fertilização in vitro. Actas do Congresso Nacional de Psicologia da Saúde: Intervenção em Psicologia e Saúde, 7, 635-638.

Freud, S. (1987). A interpretação dos sonhos. Vol. 1. (W. I. Oliveira, Trad.). São Paulo: Círculo do Livro. (Trabalho original publicado em 1900)

Freud, S. (1996a). Formulações sobre os dois princípios do funcionamento mental. In Edição standard das obras psicológicas completas de Sigmund Freud (J. Salomão, Trad., Vol. 12, pp. 233-244). Rio de Janeiro: Imago. (Original publicado em 1911)

Freud, S. (1996b). Algumas ideias sobre desenvolvimento e regressão-etiologia. In Edição standard das obras psicológicas completas de Sigmund Freud (J. Salomão, Trad., Vol. 16, pp. 343-360). Rio de Janeiro: Imago. (Trabalho original publicado em 1917)

Freud, S. (1996c). Psicologia de grupo e a análise do ego. In Edição standard das obras psicológicas completas de Sigmund Freud (J. Salomão, Trad., Vol. 18, pp. 78-154). Rio de Janeiro: Imago. (Trabalho original publicado em 1921)
Freud, S. (1996d). Inibições, sintomas e ansiedade. In Edição standard das obras psicológicas completas de Sigmund Freud (J. Salomão, Trad., Vol. 20, pp. 79-171). Rio de Janeiro: Imago. (Trabalho original publicado em 1926)

Freud, S. (1996e). Moisés e o monoteísmo, esboço de psicanálise e outros trabalhos. In Edição standard das obras psicológicas completas de Sigmund Freud (J. Salomão, Trad., Vol. 23, pp. 13-67), Rio de Janeiro: Imago. (Trabalho original publicado em 1939)

Freud, S. (1996f). Esboço de psicanálise e outros trabalhos. In Edição standard das obras psicológicas completas de Sigmund Freud (J. Salomão, Trad., Vol. 23, pp. 151-222). Rio de Janeiro: Imago. (Trabalho original publicado em 1940)

Freud, S. (2004a). À guisa de introdução ao narcisismo. In Obras psicológicas de Sigmund Freud: Vol. 1. Escritos sobre a psicologia do inconsciente (L. A. Hanns, Trad., pp. 95-132). Rio de Janeiro: Imago. (Original publicado em 1914)

Freud, S. (2004b). Pulsões e destinos da pulsão. In Obras psicológicas de Sigmund Freud: Vol. 1. Escritos sobre a psicologia do inconsciente (L. A. Hanns, Trad., pp. 133-173). Rio de Janeiro: Imago. (Original publicado em 1915)

Green, A. (1988). Narcisismo de vida, narcisismo de morte. São Paulo: Escuta.

Laplanche, J. (1998). Problemáticas I: A angústia. São Paulo: Martins Fontes.

Laplanche, J., \& Pontalis, J. B. (2001). Vocabulário da psicanálise (4a ed.). São Paulo: Martins Fontes.

Veludo, C. M. B. (2009). Narcisismo e função parental: Incursões na clínica, teoria psicanalítica e literatura. Dissertação de mestrado não publicada, Universidade de Brasília, Brasília, DF.

Winnicott, D. W. (1975). O brincar e a realidade (J. O. A. Abreu \& V. Nobre, Trads.). Rio de Janeiro: Imago.

Winnicott, D. W. (1977). A criança e o seu mundo (A. Cabral, Trad.) (4a ed.). Rio de Janeiro: Zahar.

Cássio Marcelo Batista Veludo é Mestre em Psicologia pelo Programa de Pós-graduação em Psicologia Clínica e Cultura do Instituto de Psicologia da Universidade de Brasília.

Terezinha de Camargo Viana é Professora Doutora Associada do Instituto de Psicologia da Universidade de Brasília, bolsista de Produtividade em Pesquisa do CNPq.

Recebido: 30/04/2011

$1^{a}$ revisão: $17 / 09 / 2011$

Aceite final: $22 / 12 / 2011$ 